\title{
Female Prisoners in Sindh: A Health Analysis for Policy Makers
}

\author{
* Muhammad Avais \\ ** Aijaz Wassan \\ *** Hamida Narijo
}

\begin{abstract}
Unfortunately, the self-reported health status of female prisoners in Pakistan and especially in Sindh province have not been appropriately explored or documented. No doubt, the health of female prisoners is more vulnerable as compared to male prisoners. However, neither policymakers nor social scientists paid attention to the health-related issues of female prisoners in Pakistan. Therefore, 113 (convicted: 28, under trial: 85) female prisoners in three prisons of Sindh (Karachi, Hyderabad, and Larkana) were interviewed. It was found that there is a positive correlation $(p=0.007)$ between the educational background of female prisoners and satisfaction toward available health care facilities in women prisons of Sindh province. The main objective of on-going research was to reveal the female prisoners' health status and their level of satisfaction toward provided health care facilities in the Sindh province of Pakistan. The research findings suggest that the health status of female prisoners and the impact of imprisonment on their health must be better studied at the National or provincial level for the enhancement of the health-related interventions in prisons.
\end{abstract}

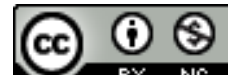

Keywords: $\quad$ Sindh, Pakistan, Female prisoners, Physical Health, Crimes, Standard Facilities Introduction

Health facilities for female prisoners are a challenging issue worldwide (Fearn \& Parker, 2005). As in other developing countries, the health issues of female prisoners are under-addressed in Pakistan. This issue has failed to grab the attention and of social scientists and also of media. Although Pakistan's government is trying to provide medical facilities for citizens, imprisoned women are still not considered by those who make government policies. This paper provides a detailed investigation of Pakistani women's health issues in the prisons of Sindh. The aim of this research is to provide insight into the health concerns of female prisoners. The main topics addressed are health issues, food quality, and the conditions of the place of imprisonment. The study revealed that female prisoners belong to the lower socio-economic segment of society. Therefore, as the socio-economic background of female prisoners is concealed from the public and policymakers, they are 'thrice marginalized'.

Because of the deviance from the natural mother care, the imprisonment of mothers may lead to damaging the family system of the society (Mignon \& Ransford, 2012). Belknap (1996) argued that in the criminal justice system, the proportion of female prisoners is very low as compared to male prisoners; thus, they are ignored in the criminal justice system dominated by males. Little access to healthy activities, nutritionally deficient food, and an unclean environment are also causes of health issues in prisons (Douglas, Plugge, \& Fitzpatrick, 2009). Female prisoners suffer from serious mental and physical issues (Anderson, 2003, Lindquist \& Lindquist, 1997). The most common problems are trauma, anxiety, and depression, along with physical abuse (Mignon, 2016). In imprisoned women, feelings of loss and loneliness lead to anxiety and depression (Carlson, 2001).

In prisons, inadequate health facilities are due to a lack of resources (Williams, 2007). Many diseases such as heart disease, asthma, hysteria, hypertension, and diabetes require regular check-ups with special care. Thus, based on their special needs from the medical perspective, health care facilities must be provided to female prisoners. Moreover, when addressing the needs of imprisoned women, basic education and indoor physical activities should be prioritized.

Research Methodology

This study was conducted through exploratory research based on scheduled interviews using the quantitative analysis technique. A non-randomized sampling technique was used to select the female

\footnotetext{
* University of Sindh Email: abdullahawais77@yahoo.com

** Email: aijaza@hotmail.com

*** Email: hnarijo@gmail.com
} 
prisoners $(\mathrm{N}=113)$ for the study period (January to June 2014) in Sindh (Karachi, Hyderabad, and Larkana) and interviewed. Because of the meager number of respondents (convicted: 28, under trial: 85), it was decided to study all prisoners. Table 1 shows the names of the prisons and jails along with the number of respondents and indicates that the majority of the respondents, $57.5 \%$, were from Karachi, 23\% were from Larkana, and $19.5 \%$ were from Hyderabad.

\begin{tabular}{lll}
\hline Name of Prison/Jail & Frequency & Percent \\
\hline Special Prison for Women Karachi & 65 & 57.5 \\
Special Prison for Women Hyderabad & 22 & 19.5 \\
Women's Jail Larkana & 26 & 23.0 \\
Total & 113 & 100.0 \\
\hline
\end{tabular}

Table 1. The Breakdown of Respondents and Locale

\section{The objective of the Study}

The aim of this research is to study the female prisoners' health-related issues in the prisons of Sindh.

Hypotheses

The below-mentioned hypotheses were formulated for the study:

1. $\mathrm{H}_{1}$ : The educational background of the respondents is likely to be related to the health of female prisoners.

2. $\mathrm{H}^{1}$ : The geographical background of the respondents is likely to be related to the health of female prisoners.

\section{Ethical Consideration}

The aims and objectives of the study were briefed to all the respondents. The study was initiated after the formal consent of female prisoners. Because of the anonymity of the respondents and the sensitivity of the research, the personal details of the respondents were not disclosed.

\section{Results}

\section{Socio-Demographic Profiling of the Respondents}

Respondents' mean age ( $\mathrm{n}=113$ ) was 33.60 , with an SD of \pm 10.97 . Table 2 shows the profiling of the respondents. It indicates that the majority of the prisoners, $71.7 \%$, were married, $4.4 \%$ were widowed, $0.9 \%$ were separated, $2.7 \%$ were divorced, and $20.4 \%$ were single. It indicates that most of the respondents, $60 \%$, were illiterate, $18.6 \%$ had primary education, $11.5 \%$ had attended secondary school, $7.1 \%$ had attended a higher secondary school, $8.8 \%$ had a degree-level, and only $0.9 \%$ had a post-graduate education. For the highest proportion of the respondents, $48.7 \%$, The family income was between RS1,000 and RS5,000, that of $38.1 \%$ was between 6,000 and 10,000 , that of $9.7 \%$ was between 11,000 and 15,000 , that of $1.8 \%$ was between 16,000 and 20,000 , and that of $1.8 \%$ was 21,000 or above. The majority of the respondents, $65 \%$, came from a rural region, and $35 \%$ came from an urban region. It was revealed that $37 \%$ of the respondents had tried to commit suicide, while $63 \%$ of them shared that they had never tried to commit suicide. It indicates that $52.2 \%$ of the respondents did not experience violence in the ir marital life, $46.7 \%$ experienced physical violence, and $1.1 \%$ were survivors of sexual violence in their marital life. Table 2 indicates that $71.7 \%$ of the respondents never experienced violence in their childhood, $20.4 \%$ experienced physical violence, and $8 \%$ were survivors of sexual violence in their childhood.

Table 2. Socio-Demographic Profiling of the Respondents

\begin{tabular}{lll}
\hline Variables & $\mathrm{N}$ & $\%$ \\
\hline Marital Status & & \\
Single (never married) & 23 & 20.4 \\
Married & 81 & 71.7 \\
Widowed & 5 & 4.4 \\
Divorced & 3 & 2.7 \\
Separated & 1 & 0.9 \\
Total & 113 & 100 \\
Educational Background & & \\
Primary & 21 & 18.6 \\
Secondary school & 13 & 11.5 \\
Higher secondary school & 8 & 7.1 \\
Graduate & 10 & 8.8 \\
Post-graduate & 10.9 \\
Illiterate & 1 & 0.9 \\
\end{tabular}




\begin{tabular}{lll}
\hline Total Income (Rs. per month) & 113 & 100.0 \\
Family & & 48.7 \\
1,000 to 5,000 & 55 & 38.1 \\
6,000 to 10,000 & 43 & 9.7 \\
11,000 to 15,000 & 11 & 1.8 \\
16,000 to 20,000 & 2 & 1.8 \\
21,000 or above & 2 & 100.0 \\
Total & 113 & 35 \\
Geographical Location & & 65 \\
Urban & 40 & 100 \\
Rural & 73 & \\
Total & 113 & 37 \\
Self-Destruction Attempt & & 63 \\
Yes & 42 & 100 \\
No & 71 & \\
Total & 113 & 52.2 \\
Abuse in Marital Life & & 46.7 \\
No & 47 & 1.1 \\
Physical & 42 & 100.0 \\
Sexual & 1 & \\
Total & 91.7 \\
Violence in Childhood & 90 & 20.4 \\
No & & 8.0 \\
Physical & 81 & 100.0 \\
Total & 23 & \\
\hline Coul
\end{tabular}

\section{Criminological Profiling of Respondents}

Table 3 shows the offenses of the respondents. It indicates that $57.5 \%$ of the offenders were behind bars due to charges for murder/attempt to murder, $5.3 \%$ for sexual crimes, $16.8 \%$ for drug-related crimes, $12.4 \%$ for kidnapping, $6.2 \%$ for robbery and theft, $0.9 \%$ for human trafficking and $0.9 \%$ for weapon trafficking.

Table 3. Offenses of the Respondents

\begin{tabular}{lll}
\hline Offenses & Frequency & Percent \\
\hline Murder/attempt to murder & 65 & 57.5 \\
Sexual crime & 6 & 5.3 \\
Drug crime & 19 & 16.8 \\
Kidnapping & 14 & 12.4 \\
Robbery and theft & 7 & 6.2 \\
Human trafficking & 1 & 0.9 \\
Weapon trafficking & 1 & 0.9 \\
Total & 113 & 100.0 \\
\hline
\end{tabular}

\section{Health and Hygiene Status of Respondents}

According to the data, 5.3\% were suffering from diabetes, $2.7 \%$ from asthma, $1.8 \%$ from stomach ulcer, $0.9 \%$ from epilepsy, $1.8 \%$ from kidney stone, $15 \%$ from high blood pressure (HTN), $8 \%$ from general fever, $2.7 \%$ from TB, $16.8 \%$ from hepatitis $\mathrm{C}, 9.7 \%$ were suffering from hepatitis $\mathrm{B}$, while $35.4 \%$ of the respondents were not suffering from any disease. Table 4 shows the satisfaction of the respondents with the available medical facilities. It indicates that $56 \%$ of the respondents were not satisfied, and $44 \%$ were satisfied with the medical facilities. The majority of the respondents, $63 \%$, were not, and $37 \%$ were satisfied with the food quality. According to most of the respondents, $76.3 \%$, their place of imprisonment is not well ventilated, and $32.7 \%$ feel that the ventilation is adequate. The majority of the respondents shared that there was inadequate light in their place of imprisonment, and $31 \%$ shared that there was sufficient light. Table 4 shows the respondents' views of the hygienic conditions. It indicates that the hygienic conditions of their place of imprisonment were worse according to $77 \%$ of the respondents; $4.4 \%$ said they were better, and $18.6 \%$ said they were normal.

Table 4. Respondents Views on Health and Hygiene Conditions of Place of Imprisonment

\begin{tabular}{lll}
\hline Variables & $\mathrm{N}$ & $\%$ \\
\hline
\end{tabular}




\begin{tabular}{lll}
\hline Hepatitis-B & 11 & 9.7 \\
Hepatitis-C & 19 & 16.8 \\
Tuberculosis (TB) & 3 & 2.7 \\
Fever & 9 & 8.0 \\
High blood pressure & 17 & 15.0 \\
Kidney stone & 2 & 1.8 \\
No disease & 40 & 35.4 \\
Epilepsy & 1 & 0.9 \\
Stomach ulcer & 2 & 1.8 \\
Asthma & 3 & 2.7 \\
Diabetes & 6 & 5.3 \\
Total & 113 & 100.0 \\
Satisfaction with the Available Medical Facilities & & \\
Yes & 50 & 44 \\
No & 63 & 56 \\
Total & 113 & 100.0 \\
Satisfaction with Food Quality & & \\
Yes & 42 & 37 \\
No & 71 & 73 \\
Total & 113 & 100 \\
Ventilation in Place of Imprisonment & & \\
Yes & 37 & 32.7 \\
No & 76 & 67.3 \\
Total & 113 & 100 \\
Light Status & & \\
Yes & 31 & 27.4 \\
No & 82 & 72.6 \\
Total & 113 & 100 \\
Hygienic Conditions & & \\
Normal & 21 & 18.6 \\
Better & 5 & 4.4 \\
Worse & 87 & 77.0 \\
Total & 113 & 100.0 \\
\hline Hypotheses Testing & & \\
\hline
\end{tabular}

Hypotheses Testing

The Chi-square test was employed for hypothesis testing.

Table 5. Chi-Square Test

\begin{tabular}{rl}
\hline Chi-Square Test for Association & \\
\hline Female Inmates $N=113$ & $P$-value \\
Satisfaction toward health facilities & .007 \\
Educational background & .786 \\
Geographical background & .
\end{tabular}

Table 5 shows the results of the Chi-square test of the hypotheses. It indicates a high association $(\mathrm{p}=0.007)$ between the education and satisfaction towards health facilities of the respondents. Therefore, the first hypothesis is accepted. However, there is no significant association $(\mathrm{p}=0.786)$ between the geographical background of the respondents and satisfaction towards health facilities. Therefore, the second hypothesis is rejected.

\section{Discussion}

In Pakistan, the general and medical issues of female prisoners are concealed from the public. Moreover, this issue is little addressed by social scientists and media. Thus, this study was conducted to obtain data related to female prisoners' health status in Sindh and their views of the available food quality, medical facilities, and hygienic conditions in the place of imprisonment. A high proportion of the respondents, $53.1 \%$, was illiterate, $65 \%$ came from a rural region. While $56 \%$ of the respondents were unsatisfied with the available health care facilities. The number of married women in prisons is higher as compared to single prisoners, $71.7 \%$. The results of this study are different from the results of Sarpong et al. (2015) and Nobile, Flotta, Nicotera, Pileggi \& Angelillo (2011), who reported that married women are less likely to be involved in illegal activities and perceptions of the quality of health care depend on the background of the female prisoners. Further, the result of the current study strengthens the results of Avais \& Wassan (2017), who concluded in a study on female criminals in 
Pakistan that the majority of convicted female prisoners, $85.7 \%$ in Sindh and Punjab province, were married at the time of the commission of the crime. It was found that $2.7 \%$ of the respondents suffer from TB. It is shocking that inadequate lighting arrangements were identified by $72.6 \%$ of the respondents and $67.3 \%$ of the respondents shared that there is improper ventilation in their place of imprisonment. Such an environment is very suitable for several infectious diseases. In addition, such an environment has a negative effect on the health of female prisoners through such conditions as hepatitis, arthritis, menopause, and TB (Das, 2013). The prisons contribute to spreading TB (Reyes \& Coninx, 1997), a threat to both the general population and the population behind bars (Greifinger, Heywood, \& Glaser, 1993).

The study shows that $9.7 \%$ of the respondents were suffering from hepatitis-B and $16.8 \%$ from hepatitis-C. Eventually, after releasing infected prisoners, infectious diseases that are untreated in prisons will spread in society (Stead, 1978). Hepatitis $\mathrm{C}$ is a major threat for female prisoners as there is no vaccination available for it. The family income of $48.7 \%$ of the respondents was between 1,000 and 5,000 rupees per month. 33.60 was the mean age of the respondents, with an SD of \pm 10.97 . Of the respondents, $20.4 \%$ were physically and $8 \%$ sexually abused in their childhood, and $46.7 \%$ were physically and $1.1 \%$ sexually abused in their marital life. Of the respondents, $57.5 \%$ were behind bars due to a charge of murder/attempt to murder, $77 \%$ were unsatisfied with the hygienic conditions of their place of imprisonment, and $63 \%$ were said that the food quality was unsatisfactory. Moreover, $37 \%$ of the respondents had tried to commit suicide, which shows psychological issues among the prisoners. Several studies have identified that in prisons, mental health issues are common (Brinded, Simpson, Laidlaw, Fairley, \& Malcolm, 2001, Corrado, Cohen, Hart, \& Roesch, 2000, Fazel \& Danesh, 2002, Watson, Stimpson, \& Hostick, 2004). Therefore, the lack of treatment for female prisoners to commit suicide may lead to the worsening of their serious mental disorders over time. For prisoners with suicidal intentions, the prison environment is considered as a high-risk, and the link between mental disorders and suicide is commonly known (WHO, 2000). The study focused on only female prisoners who are Pakistani nationals. Thus, the results may not be generalized.

\section{Conclusion}

It is a challenge for the government and the department of corrections to provide high-quality health services to female prisoners in Sindh. Moreover, unhygien ic conditions of the places of imprisonment, inadequate food, and infectious diseases are serious threats. The respondents represent a vulnerable and marginalized population in terms of the presence of prisoners with mental health disorders (previous suicide attempts) or infectious diseases, childhood or marital abuse, unhygienic conditions of the place of imprisonment, lack of education, and poverty. According to this research, the current medical health facilities for female prisoners are insufficient for the needs of respondents. Thus, in Sindh, government policies should address the needs of imprisoned women at the national level. In addition, in prisons, female gynecologists must be available for women because of the specific health issues of female prisoners.

\section{References}

Anderson, T. L. (2003). Issues in the availability of health care for women prisoners. The incarcerated woman: Rehabilitative programming in women's prisons, 49-60.

Avais, M. A., \& Wassan, A. A. (2017). Female Criminals A Socio-Criminological Analysis of Pakistan. Grassroots, 51(1).

Belknap, J. (1996). Access to programs and health care for incarcerated women. Fed. Probation, 60, 34.

Bloom, B. E., \& Covington, S. (2008). Addressing the mental health needs of women offenders. Women's mental health issues across the criminal justice system, 160-176.

Brinded, P. M., Simpson, A. I., Laidlaw, T. M., Fairley, N., \& Malcolm, F. (2001). Prevalence of psychiatric disorders in New Zealand prisons: a national study. Australian \& New Zealand Journal of Psychiatry, 35(2), 166-173.

Carlson, J. R. (2001). Prison nursery 2000: A five-year review of the prison nursery at the Nebraska Correctional Center for Women. Journal of Offender Rehabilitation, 33(3), 75-97.

Corrado, R. R., Cohen, I., Hart, S., \& Roesch, R. (2000). Comparative examination of the prevalence of mental disorders among jailed inmates in Canada and the United States. International Journal of Law and Psychiatry, 23(5-6), 633-647.

Das, S. (2013). Women Prisoners in Odisha: A Socio-Cultural Study (Doctoral dissertation). 
Douglas, N., Plugge, E., \& Fitzpatrick, R. (2009). The impact of imprisonment on health: what do women prisoners say?.Journal of Epidemiology \& Community Health, 63(9), 749-754.

Fazel, S., \& Danesh, J. (2002). Serious mental disorder in 23000 prisoners: a systematic review of 62 surveys. The lancet, 359(9306), 545-550.

Fearn, N. E., \& Parker, K. (2005). Health care for women inmates: Issues, perceptions and policy considerations. Californian Journal of Health Promotion, 3(2), 1-22.

Greif inger, R. B., Heywood, N. J., \& Glaser, J. B. (1993). Tuberculosis in prison: balancing justice and public health. The Journal of Law, Medicine \& Ethics, 21(3-4), 332-341.

Lindquist, C. H., \& Lindquist, C. A. (1997). Gender differences in distress: Mental health consequences of environmental stress among jail inmates. Behavioral Sciences \& the Law, 15(4), 503-523.

Mignon, S. (2016). Health issues of incarcerated women in the United States. Ciência \& Saúde Coletiva, 21(7), 2051-2060.

Mignon, S. I., \& Ransford, P. (2012). Mothers in prison: Maintaining connections with children. Social Work in Public Health, 27(1-2), 69-88.

Nobile, C. G., Flotta, D., Nicotera, G., Pileggi, C., \& Angelillo, I. F. (2011). Self-reported health status and access to health services in a sample of prisoners in Italy. BMC Public Health, 11(1), 529.

Organization, W. H. (2000). Preventing suicide: a resource for prison officers Mental and Behavioural Disorders (WHO): World Health Organization.

Reyes, H., \& Coninx, R. (1997). Pitfalls of tuberculosis programmes in prisons. BMJ: British Medical Journal, 315(7120), 1447.

Sarpong, A., Otupiri, E., Yeboah-Awudzi, K., Osei-Yeboah, J., Berchie, G., \& Ephraim, R. (2015). An Assessment of Female Prisoners' Perception of the Accessibility of quality Healthcare: A Survey in the Kumasi Central Prisons, Ghana. Annals of medical and health sciences research, 5(3), 179-184.

Stead, W. W. (1978). Undetected tuberculosis in prison: source of infection for community at large. Jama, 240(23), 2544-2547.

Watson, R., Stimpson, A., \& Hostick, T. (2004). Prison health care: a review of the literature. International journal of nursing studies, 41(2), 119-128.

Williams, N. H. (2007). Prison health and the health of the public: Ties that bind. Journal of Correctional Health Care, 13(2), 80-92. 